\title{
ANALISIS ENERGI LISTRIK DARI PANAS KONDENSOR AIR CONDITIONER DENGAN INSULASI DAN GENERATOR TERMOELEKTRIK
}

\author{
Electrical Energy Analysis of Air Conditioner Condenser Heat with Insulation and \\ Thermoelectric Generator
}

Sri Poernomo Sari ${ }^{1 *}$, Depi Kurniawan Saputra ${ }^{1}$ dan Donawan ${ }^{1}$

${ }^{1}$ Program Studi Teknik Mesin, Universitas Gunadarma, Jl. Margonda Raya no. 100, Indonesia

Informasi artikel

Diterima: $11 / 05 / 2019$ Direvisi : 17/05/2019 Disetujui: 20/05/2019

\begin{abstract}
Abstrak
Tujuan penelitian adalah menganalisis energi termal yang dihasilkan dari kondensor air conditioner menjadi energi listrik dengan insulasi dan generator termoelektrik. Ducting bahan plat aluminium dengan ketebalan $1.2 \mathrm{~mm}$ berbentuk silinder, diameter $355 \mathrm{~mm}$, panjang 100 $\mathrm{mm}$ dan $200 \mathrm{~mm}$ digunakan untuk menampung udara panas dari kondensor. Ducting dihubungkan dengan sisi panas generator termoelektrik, heatsink dan fan dipasang di bagian sisi dingin termoelektrik untuk menjaga kestabilan temperatur. Pengujian dilakukan untuk ducting menggunakan insulasi glasswool dan rockwool dengan ketebalan $4 \mathrm{~mm}$. Pengujian untuk ducting $100 \mathrm{~mm}$ menggunakan insulasi rockwool dan glasswool dengan ketebalan $4 \mathrm{~mm}$ menghasilkan daya listrik rata-rata 0.018 dan 0.015 Watt, ducting 200 $\mathrm{mm}$ menghasilkan 0.015 dan 0.012 Watt. Daya listrik rata-rata yang dihasilkan dari panas kondensor untuk ducting $100 \mathrm{~mm}$ dan $200 \mathrm{~mm}$ dengan insulasi rockwool $26.76 \%$ dan $25.25 \%$ lebih besar dari pada glass wool.
\end{abstract}

Kata Kunci: Energi listrik, kondensor, air conditioner, insulasi, generator termoelektrik.

\begin{abstract}
The purpose of the research is analyzing the thermal energy produced from air conditioner condenser into electrical energy with insulation and thermoelectric generator. Ducting aluminum plate with a thickness of $1.2 \mathrm{~mm}$ in the shape of a cylinder, diameter of $355 \mathrm{~mm}$, length of $100 \mathrm{~mm}$ and $200 \mathrm{~mm}$ is used to hold hot air from the condenser. Ducting is connected to the thermoelectric generator heat side, heatsinks and fans are installed on the cold side of the thermoelectric to maintain temperature stability. Tests are carried out for ducting using rockwool and glass wool insulation with a thickness of $4 \mathrm{~mm}$. Testing for $100 \mathrm{~mm}$ ducting using rockwool and glass wool insulation with a thickness of $4 \mathrm{~mm}$ produces an average electric power of 0.018 and 0.015 Watt, $200 \mathrm{~mm}$ ducting produces 0.015 and 0.012 Watt. Power generated from condenser heat for ducting $100 \mathrm{~mm}$ and $200 \mathrm{~mm}$ with rockwool insulation are $26.76 \%$ and $25.25 \%$ greater than glass wool.
\end{abstract}

Keywords: Electric energy, condenser, air conditioner, insulation, thermoelectric generator.

*Penulis Korespondensi : Handphone: 085880423336

email : sri_ps@staff.gunadarma.ac.id 


\section{PENDAHULUAN}

Peningkatan kebutuhan manusia untuk memenuhi suatu tingkat kualitas hidup tidak dapat dihindari. Potensi sumber daya alam yang ada senantiasa dapat selalu diekspos oleh manusia guna memenuhi kebutuhan hidupnya, namun tidak selamanya manusia menggantungkan diri dari sumber daya alam tersedia di bumi karena sifatnya terbatas. Upaya dilakukan dengan cara menghemat energi atau menggunakan kembali energi yang telah digunakan sebelumnya. Metode konservasi energi yang tepat dapat memperpanjang masa habis sumber energi berbahan dasar sumber daya alam. Sektor perindustrian membutuhkan sumber energi listrik dimana salah satu sumber pembangkit listrik adalah sumber daya alam namun membutuhkan sumber energi bahan bakar fosil.

Secara umum efisiensi termal masih berlangsung sangat rendah, yang lain merupakan panas yang dibuang ke lingkungan. Energi listrik dapat disalurkan kembali ke berbagai kebutuhan instrumen berdaya listrik dengan pemanfaatan panas buang yang besar ke lingkungan ini. Penggunaan air conditioner menghasilkan energi panas dari kerja kondensor. Panas kondensor akan ke atmosfir dan menjadi polusi termal. Panas yang tidak terpakai ini berada pada kisaran rendah antara temperatur $25^{\circ} \mathrm{C}$ hingga $200^{\circ} \mathrm{C}$. Energi termal yang terbuang dapat dimanfaatkan dengan bantuan generator termoelektrik menjadi pilihan untuk mengkonversikan energi termal yang terbuang menjadi energi listrik. Tujuan penelitian adalah menganalisis energi termal yang dihasilkan dari kondensor air conditioner menjadi energi listrik dengan insulasi dan generator termoelektrik.

\section{METODOLOGI}

Konversi energi panas menjadi energi listrik dengan memanfaatkan panas yang dihasilkan kondensor air conditioner dengan ducting dilapisi bahan insulasi rockwool, glasswool dan generator termoelektrik. Penggunaan ducting untuk pemanfaatan udara panas kondensor berbahan plat aluminium diameter $355 \mathrm{~mm}$ panjang $100 \mathrm{~mm}$ dan $200 \mathrm{~mm}$ dan tebal plat $1.2 \mathrm{~mm}$ (lihat gambar 1).

Generator termoelektrik yang digunakan adalah seri TEG12706 sebanyak 14 buah. Pada alat uji terdapat 3 buah termometer digital yang berguna untuk mengetahui temperatur fluida awal ducting, temperatur ujung ducting yang dirambati panas yang keluar dari kondensor dan temperatur heatsink. Ducting dilapisi bahan insulasi jenis rockwool dan glasswool dengan tebal $4 \mathrm{~mm}$ agar panas yang dihasilkan oleh kondensor tidak keluar atau berkurang. Ducting ini berfungsi untuk menyimpan udara panas yang akan dikonversikandari udara panas menjadi energi listrik dengan bantuan generator listrik yang disebut termoelektrik. Penggunaan material ini dikarenakan bahwa alumunium merupakan konduktor yang baik dalam menyalurkan udara panas yang dikeluarkan oleh kondensor. Dalam sistem ducting kondensor ini terdapat tiga buah komponen yaitu cubeducting, cylinder ducting, dan casing cylinder ducting.
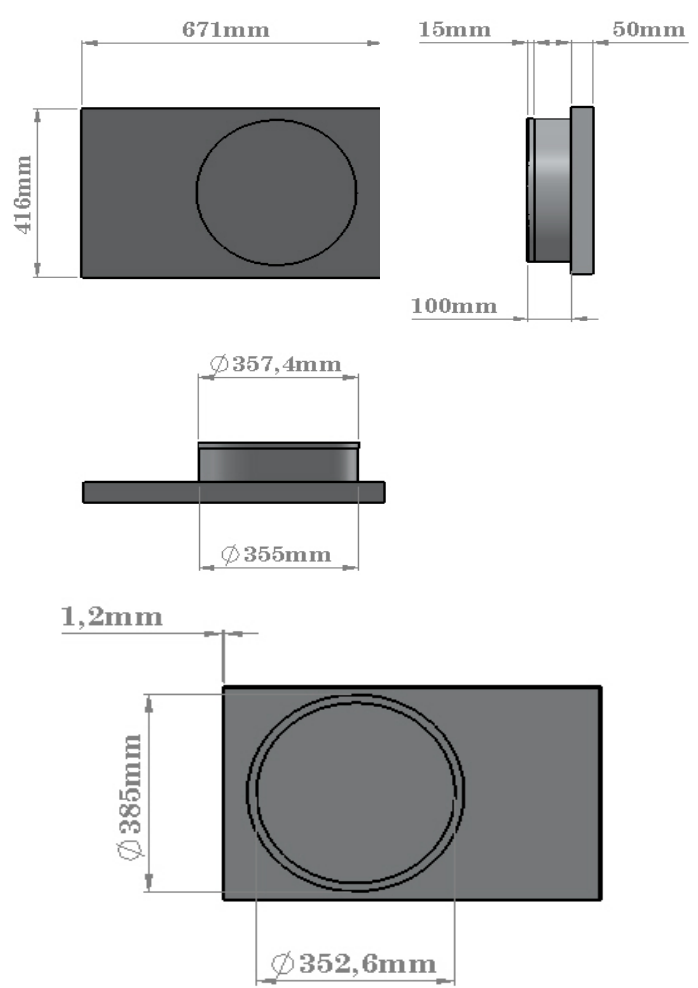

Gambar 1 Ducting 100 mm

Kondensor komponen dalam sistem refrigerasi yang berfungsi untuk melepas panas dari refrigeran agar terjadi pengembunan. Kondensor yang digunakan dalam penelitian ini adalah kondensor air conditioner jenis split kapasitas $1 \mathrm{PK}$. 
Heatsink adalah logam dengan desain khusus yang terbuat dari alumunium yang berfungsi untuk memperluas transfer panas dari sebuah permukaan. Semakin luas permukaan perpindahan panas maka akan semakin cepat proses pendinginannya. Oleh karena itu penggunaan heatsink dalam penelitian ini berguna untuk mendinginkan sisi dingin dari termoelektrik agar terjadi perbedaan temperatur sehingga menimbulkan perbedaan potensial listrik (lihat gambar 2).

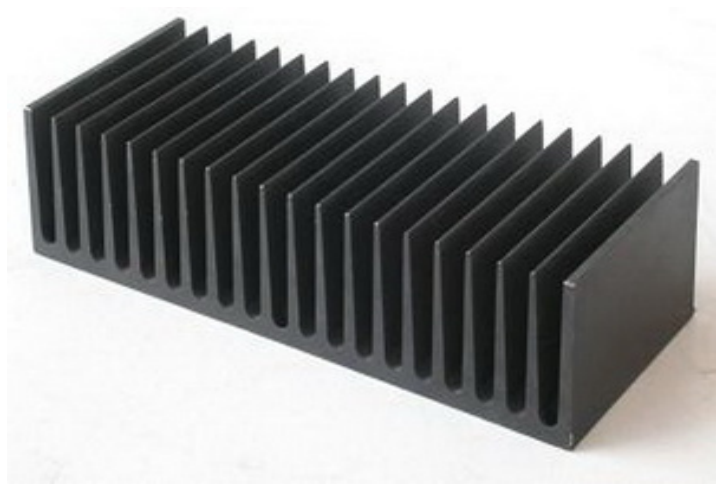

Gambar 2 Heatsink Alumunium

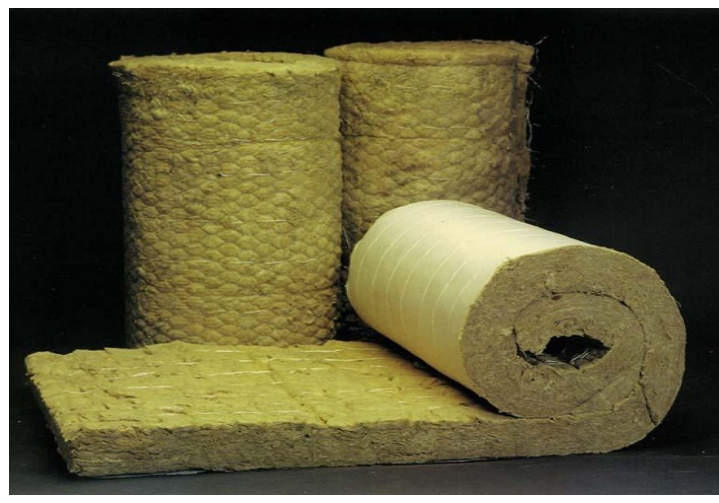

Gambar 3 Rockwool

Bahan insulasi berguna untuk mencegah panas merambat atau masuk kedalam material lain. Bahan insulasi digunakan untuk melapisi ducting agar udara panas yang mengalir di dalam ducting tidak keluar dan panas lingkungan atau dari luar tidak masuk ke dalam ducting. Sehingga - 67 -emperature di dalam ducting hanya berasal dari kerja kondensor. Jenis bahan insulasi yang digunakan dalam penelitian ini berjenis rockwool (lihat gambar 3) dan glasswool (lihat gambar 4). Pemilihan jenis insulasi ini dikarenakan dari panas ducting kurang dari $90^{\circ} \mathrm{C}$. Tembaga adalah konduktor yang baik dalam perambatan panas atau perambatan listrik. Penggunaan kawat tembaga dalam penelitian ini berguna untuk menyambung termoelektrik pada junction terminal agar dapat membuat rangkaian listrik seri.

Termoelektrik merupakan teknologi yang bekerja mengkonversikan energi panas menjadi energi listrik secara langsung, atau sebaliknya dari energi listrik menjadi energi panas dan dingin (lihat gambar 5). Prinsip kerja termoelektrik ini menggunakan prinsip efek seebeck yang artinya jika dua buah logam yang berbeda disambungkan pada salah satu ujungnya kemudian dipanaskan sehingga timbul perbedaan panas pada sambungannya maka akan terjadi perbedaan tegangan pada ujung satu dengan ujung yang lainnya. Pada ducting ini permukaan tutup silinder ducting akan terkena udara panas yang dibuang oleh kondensor yang berdampak terjadinya pemanasan pada permukaan tutup silinder tersebut, dan kemudian akan dimanfaatkan energi panas tersebut oleh termoelektrik yang akan diubah menadi energi listrik.

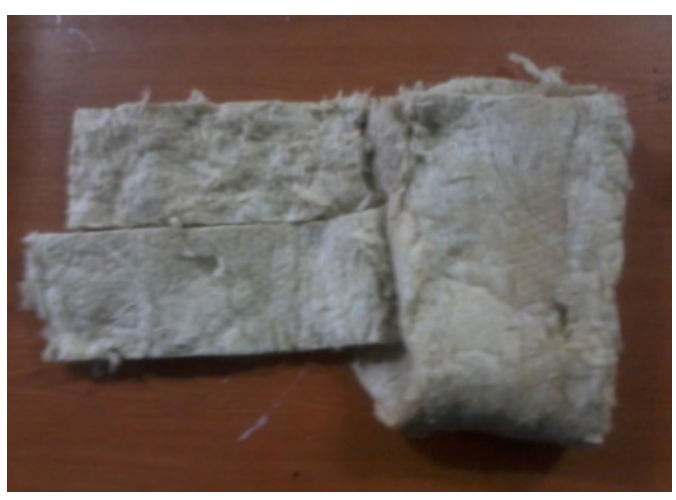

Gambar 4 Glasswool

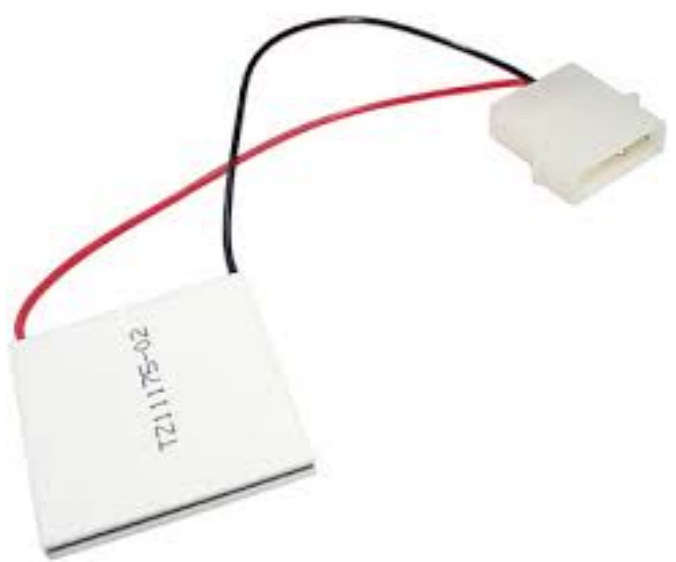

Gambar 5 Generator Termoelektrik 
Juction terminal berfungsi untuk menghubungkan beberapa termoelektrik yang digunakan pada ducting kondensor menjadi rangkaian seri (lihat gambar 6 dan 7).

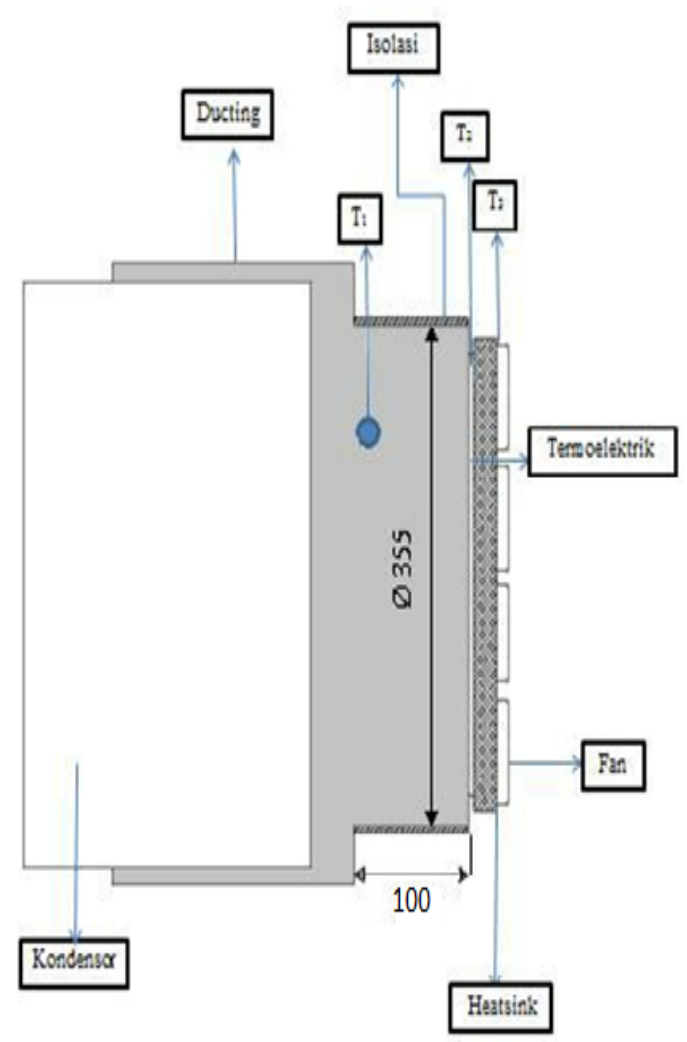

Gambar 6 Eksperimental set-up alat uji ducting $100 \mathrm{~mm}$

Cylinder ducting $100 \mathrm{~mm}$ dan $200 \mathrm{~mm}$ dilapisi dengan rockwool dan glasswool tebal $4 \mathrm{~mm}$ secara menyeluruh. Air Conditioner yang telah terdapat ducting kondensor dinyalakan dengan temperatur $16^{\circ} \mathrm{C}$. Temperatur pada awal silinder didalam ducting $200 \mathrm{~mm}$ diukur menggunakan termometer digital ketika kondensor telah mulai mengeluarkan udara panasnya.

Temperatur awal cylinder mencapai temperatur maksimal. Temperatur pada covercylinder dan heatsink diukur dengan termometer digital ketika temperatur awal silinder telah maksimal kemudian mencatat hasil perubahan temperatur tersebut. Tegangan dan arus diukur dari rangkaian seri secara bertahap dari modul generator termoelektrik (TEG) 1 hingga 14. Hasil tegangan dan arus didapatkan dari temperatur maksimal.

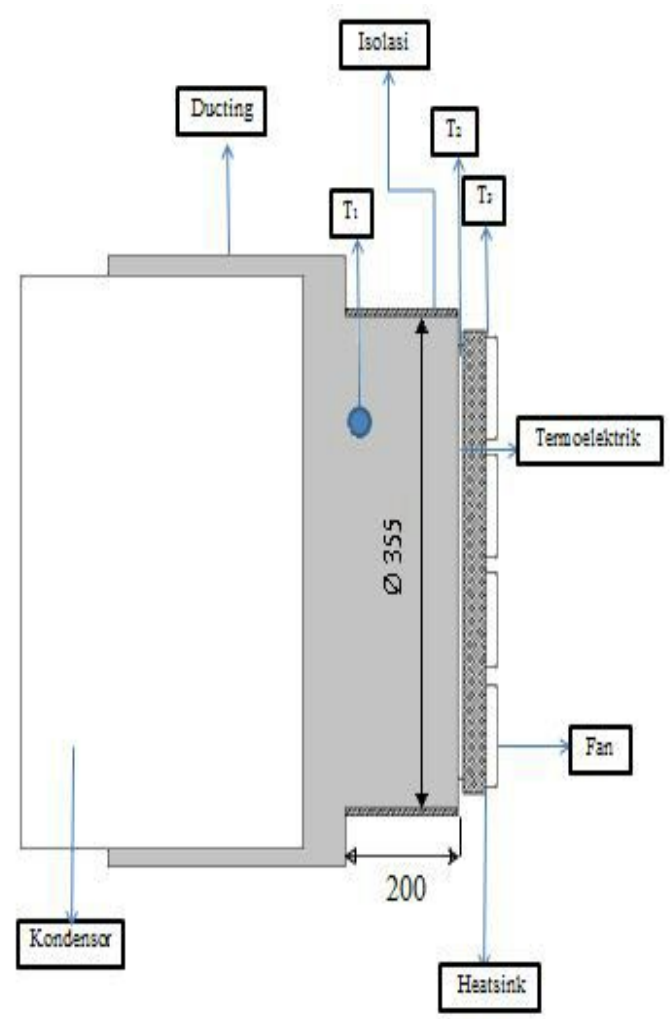

Gambar 7 Eksperimental set-up alat uji ducting $200 \mathrm{~mm}$

Keterangan

$\mathrm{T} 1=$ Temperatur awal didalam ducting $\left({ }^{\circ} \mathrm{C}\right)$

$\mathrm{T} 2=$ Temperatur cover casing cylinder $\left({ }^{\circ} \mathrm{C}\right)$

$\mathrm{T} 3=$ Temperatur heatsink $\left({ }^{\circ} \mathrm{C}\right)$

Analisis rangkaian yang dibahas adalah peralihan energi yang timbul sebagai akibat terdapatnya tegangan atau beda potensial listrik dan arus listrik pada rangkaian. Tegangan dan arus dalam rangkaian tersebut dapat diperoleh besarnya daya yang listrik.

$$
\mathrm{P}=\mathrm{V} \times \mathrm{I}
$$

Suatu rangkaian tidak selalu diketahui besarnya tegangan yang mengalir, oleh karena itu bila dalam suatu rangkaian diketahui besarnya hambatan dan arus listrik yang terdapat di dalam rangkaian, maka dapat diperoleh tegangan dengan menggunakan persamaan (2).

$$
V=I \times R
$$


Dimana :

$\mathrm{P}=$ Daya listrik (Watt)

$\mathrm{V}=$ Tegangan listrik (Volt)

$\mathrm{I}=$ Arus listrik (Ampere)

$\mathrm{R}=$ Resistor/Hambatan (Ohm)

Rangkaian seri merupakan suatu rangkaian listrik yang disusun sejajar. Cara kerja rangkaian seri adalah membagi arus yang dihasilkan komponen lain. Apabila terdapat 3 buah rangkaian yang dirangkai secara seri, maka tegangan yang dihasilkan dari satu buah rangkaian akan memberikan sisa tegangan yang dihasilkan sehingga proses ini memungkinkan dapat mengurangi pamakaian tegangan.

Kelebihan dari rangkaian seri adalah memiliki lebih banyak menghemat daya yang dikeluarkan pada baterai, pembuatan atau pengerjaan yang singkat dan tidak memerlukan banyak penghubung pada penyambung jalur.

Resistor (Hambatan)

$$
R_{s}=R_{1}+R_{2}+\ldots . R_{n}
$$

Arus Listrik

$$
I_{t}=I_{1}+I_{2}+\ldots . . I_{n}
$$

Tegangan Listrik

$$
\mathrm{V}_{\mathrm{ts}}=\mathrm{V}_{1}+\mathrm{V}_{2}+\ldots . \mathrm{V}_{\mathrm{n}}
$$

Dimana :

$\mathrm{R}_{\mathrm{s}}=$ Hambatan total rangkaian seri (Ohm)

$\mathrm{I}_{\mathrm{t}}=$ Arus total yang mengalir pada rangkaian seri (Ampere)

$\mathrm{V}_{\mathrm{ts}}=$ Tegangan total rangkaian seri (Volt)

\section{HASIL DAN PEMBAHASAN}

Data pengujian berupa temperatur dalam celcius, tegangan dan arus listrik yang mengalir dengan menggunakan multitester. Temperatur dibedakan menjadi tiga jenis yaitu temperatur awal, temperatur penampang termoelektrik dan temperatur heatsink. Temperatur awal adalah temperatur yang diukur pada posisi udara awal keluar dari kondensor. Temperatur penampang adalah temperatur yang terdapat pada penampang termoelektrik yang didapat dari hasil perambatan panas melalui ducting kondensor, dan temperatur heatsink adalah temperatur pendingin dari sisi dingin termoelektrik.

Tegangan dan arus listrik didapat dari multitester, data tegangan dan arus diukur dari setiap masing-masing termoelektrik sampai dibuat menjadi rangkaian listrik seri dari 14 buah termoelektrik. Pengambilan data temperatur ini berguna untuk mengetahui perbedaan temperatur dari $T_{2}$ dan $T_{3}$. Perbedaan temperatur dari $T_{2}$ dan $T_{3}$ adalah temperatur yang diterima oleh termoelektrik. Data temperatur didapat dari pengamatan pada termometer digital yang diletakkan pada ducting kondensor.

Pengamatan dilakukan ketika AC dihidupkan dan diatur dengan tingkat temperatur dingin ruang sebesar $16^{\circ} \mathrm{C}$. Temperatur ruang dengan tingkat pengatur sebesar $16^{\circ} \mathrm{C}$ merupakan tingkat kerja kondensor yang paling tinggi, Pengamatan temperatur ini berguna untuk mengetahui perbedaan temperatur yang mengenai termoelektrik, sehingga diketahui perbedaan temperatur atau $\Delta \mathrm{T}$ yang mempengaruhi termoelektrik untuk bekerja. Waktu pelaksanaan pengambilan data dilakukan pada pukul 12.00 WIB (lihat tabel 1).

Tabel 1 Temperatur ducting dengan insulasi rockwool dan glasswool panjang $100 \mathrm{~mm}$ dan tebal $4 \mathrm{~mm}$

\begin{tabular}{cccc}
\hline Bahan & $\mathrm{T} 1\left({ }^{\circ} \mathrm{C}\right)$ & $\mathrm{T} 2\left({ }^{\circ} \mathrm{C}\right)$ & $\mathrm{T}_{3}\left({ }^{\circ} \mathrm{C}\right)$ \\
Insulasi & & & \\
\hline Rockwool & 71 & 57 & 36 \\
Glasswool & 67.2 & 55.3 & 35 \\
\hline
\end{tabular}

Keterangan:

$\mathrm{T} 1=$ Temperatur awal kondensor $\left({ }^{\circ} \mathrm{C}\right)$

$\mathrm{T} 2$ = Temperatur penampang termoelektrik $\left({ }^{\circ} \mathrm{C}\right)$

$\mathrm{T} 3=$ Temperatur heatsink $\left({ }^{\circ} \mathrm{C}\right)$ 
Data pengujian ini didapat dari perbedaan temperatur yang terjadi dari $\mathrm{T}_{2}$ dan $T_{3}$. Temperatur $\mathrm{T}_{3}$ diperoleh menggunakan heatsink yang didinginkan menggunakan kipas arus ac agar terjaga kestabilan temperaturnya. Besarnya perbedaan temperatur ini yang akan diterima oleh termoelektrik untuk dikonversikan menjagi energi listrik. Perbedaan temperatur menyebabkan perbedaan potensial didalam termoelektrik (lihat tabel 2).

Tabel 2 Temperatur ducting dengan insulasi rockwool dan glasswool panjang $200 \mathrm{~mm}$ dan tebal $4 \mathrm{~mm}$

\begin{tabular}{cccc}
\hline $\begin{array}{c}\text { Bahan } \\
\text { Insulasi }\end{array}$ & $\mathrm{T} 1\left({ }^{\circ} \mathrm{C}\right)$ & $\mathrm{T} 2\left({ }^{\circ} \mathrm{C}\right)$ & $\mathrm{T}_{3}\left({ }^{\circ} \mathrm{C}\right)$ \\
\hline Rockwool & 63.4 & 53.5 & 38.7 \\
Glasswool & 63.3 & 53.7 & 35 \\
\hline
\end{tabular}

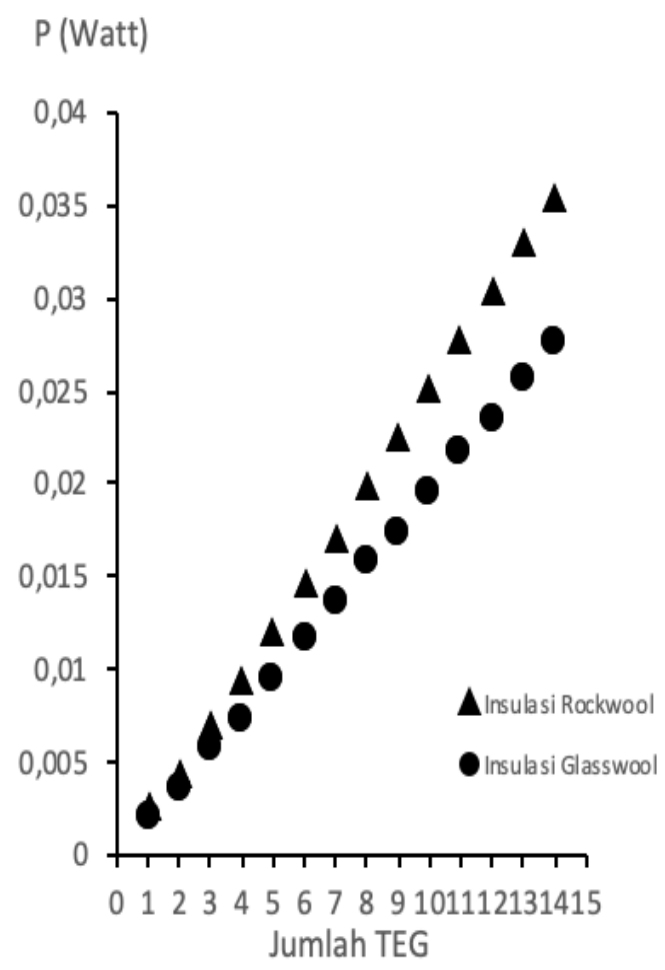

Gambar 8 Grafik hubungan antara jumlah generator termoelektrik (TEG) terhadap Daya $(\mathrm{P})$ listrik yang dihasilkan dari panas kondensor pada ducting $100 \mathrm{~mm}$ dengan insulasi rockwool dan glasswool
Dapat dilihat pada gambar 8 material rockwool dapat menahan panas lebih baik, hingga daya listrik kurang lebih 0,035 Watt. Sebaliknya material glasswool yang mana dapat menahan hingga daya listrik kurang lebih 0,027 Watt. Perubahan terjadi dengan jumlah TEG sebanyak 3 modul. Pada jumlah modul TEG 4 modul, perbedaan kemampuan meredam panas mulai terlihat dengan sangat jelas.

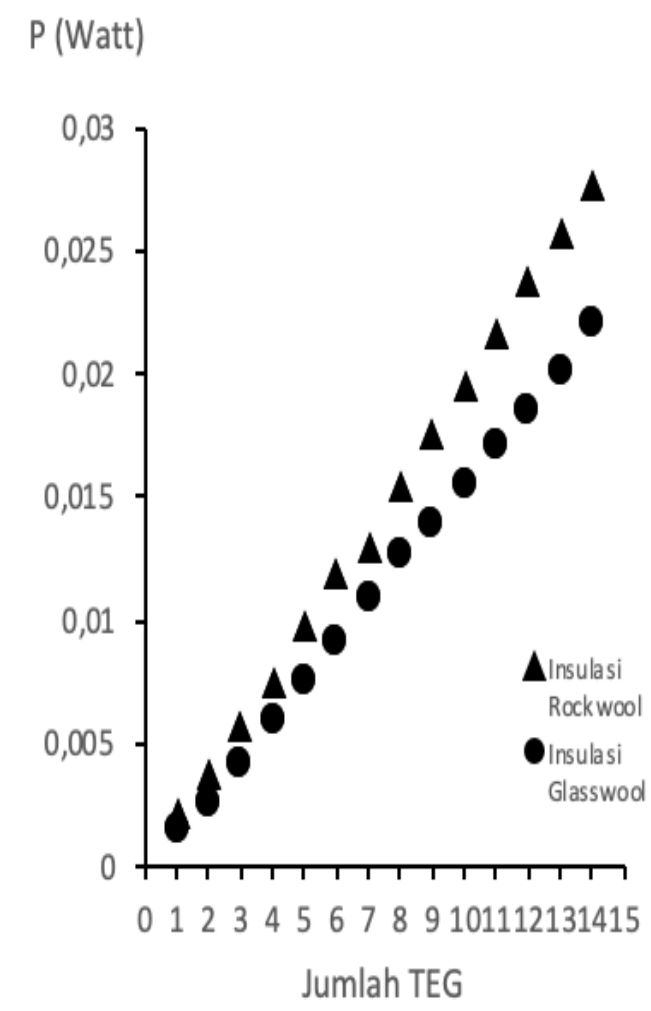

Gambar 9 Grafik hubungan antara jumlah generator termoelektrik (TEG) terhadap Daya $(P)$ listrik yang dihasilkan dari panas kondensor pada ducting $200 \mathrm{~mm}$ dengan insulasi rockwool dan glasswool

Pada gambar 9 , dengan ducting ukuran $200 \mathrm{~mm}$, material rockwool dapat menahan panas lebih baik, hingga daya listrik kurang lebih 0,027 Watt. Sebaliknya material glasswool masih dibawahnya, perbedaan yang mencolok ada pada jumlah modul TEG sebanyak 2 modul. Perbedaan jelas pada jumlah modul TEG sebanyak 3 modul. Ada terjadi error data pada modul TEG dengan jumlah 4 dan 7 modul, hal ini terjadi karena perubahan suhu ruang yang tiba-tiba. Sehingga menyebabkan data error. 


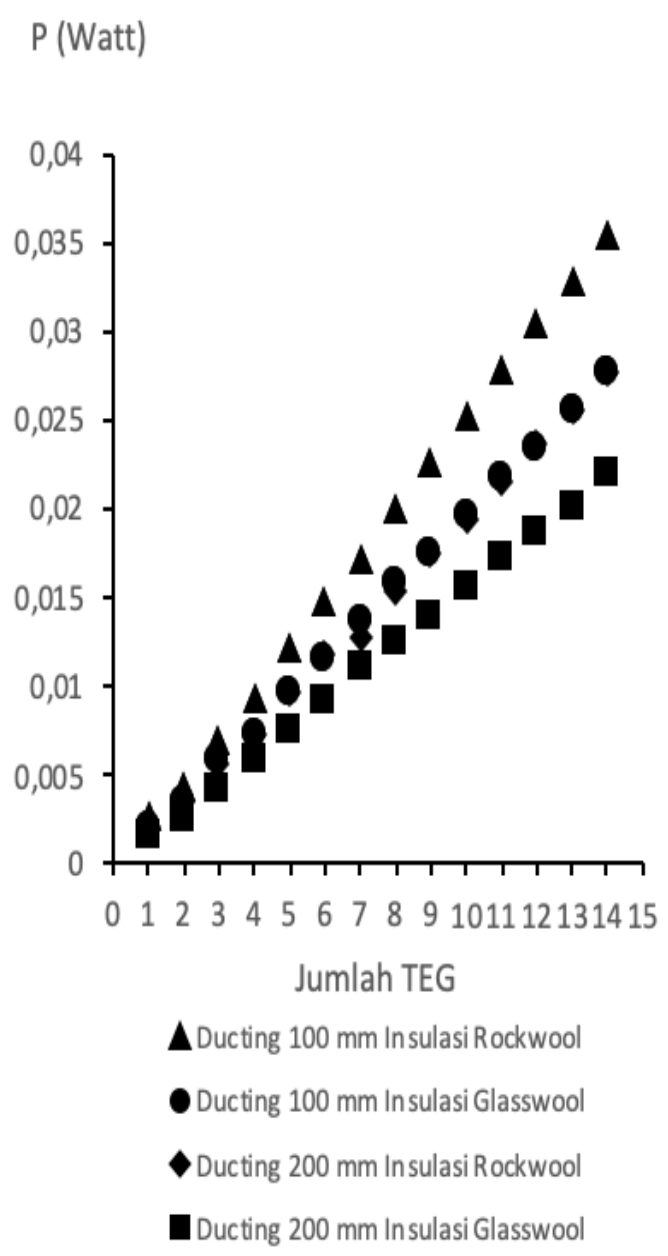

Gambar 10 Grafik hubungan antara jumlah generator termoelektrik (TEG) terhadap Daya $(P)$ listrik yang dihasilkan dari panas kondensor pada ducting $100 \mathrm{~mm}$ dan 200 $\mathrm{mm}$ dengan insulasi rockwool dan glasswool

Pada gambar 10 menunjukkan hubungan antara jumlah generator termoelektrik (TEG) terhadap Daya (P) listrik yang dihasilkan dari panas kondensor pada ducting $100 \mathrm{~mm}$ dan $200 \mathrm{~mm}$ dengan insulasi rockwool dan glasswool. Pada ducting 100 $\mathrm{mm}$ dengan insulin glasswool memiliki kesamaan data dengan ducting $200 \mathrm{~mm}$ dengan insulin rockwool. Hal ini membuktikan bahwa dengan parameter tersebut memiliki hasil atau kemampuan yang sama.

Berdasarkan grafik pada gambar 8, 9 dan 10 dapat disimpukan bahwa bahan insulasi rockwoll dapat menahan panas lebih tinggi daripada bahan glasswool sehingga daya listrik yang dihasilkan dari panas kondensor pada ducting yang dilapisi bahan insulasi rockwool lebih besar daripada glasswool. Panas kondensor yang dikumpulkan pada ducting dengan panjang $100 \mathrm{~mm}$ menghasilkan daya listrik lebih besar daripada $200 \mathrm{~mm}$.

\section{SIMPULAN}

Panas yang dihasilkan dari kerja kondensor air conditioner dapat dimanfaatkan sebagai energi listrik dengan mengkonversikan energi termal ke energi listrik. Semakin panjang ukuran ducting yang digunakan untuk mengumpulkan panas kondensor maka semakin kecil rendah daya listrik rata-rata yang dihasilkan. Ducting yang dilapisi bahan insulasi rockwool dapat menghasilkan daya listrik yang lebih besar daripada glasswool.

\section{DAFTAR PUSTAKA}

Daubert, T.E, Chemical Engineering Thermodynamics.1985. International Edition, Singapore: Mc-Graww Hill, Inc.

Holman, J.P.1986. Heat Transfer Sixth Edition, Mcgraw-Hill, Inc. New York.

Stocker. WR, 1987, Refrigerasi dan Pengkondisian Udara, Jakarta, Penerbit Erlangga.

Sadik Kakaç, 1991, Boilers, Evaporators, and Condensers, Manchester, John Wiley \& Sons.

Kreith. Frank. 2010. Manglik. Raj,Mark Bohn, Principles of Heat Transfer, Paris, Cengage Learning.

Ryanuargo, Anwar Syaiful dan Sri Poernomo Sari.2013. Generator Mini Dengan Prinsip Termoelektrik Dari Uap Panas Kondensor Pada Sistem Pendingin. Jurnal Rekayasa Elektrika, Universitas Syiah Kuala. Volume 10, No: 4.

Sri Poernomo Sari, Pujang Setia, Trivani Achirudin, Bambang Suryawan. 2015. Kajian Eksperimental Pemanfaatan Panas Buang Kondensor Air Conditioning Sebagai Alternatif Penghasil Energi Listrik dengan Bantuan Generator Termoelektrik. Prosiding Konferensi Nasional Engineering Perhotelan VI2015. ISSN 2338-414X, Nomor $1 /$ Volume 3/Juli2015. Jurusan Teknik Mesin, Fakultas Teknik, Universitas Udayana.11-12 Juni 2015. 
Sri Poernomo Sari, Trivani Achirudin, Irdiyansyah. 2016. Kajian Awal Analisis Kalor Buang Kondensor Pendingin Ruangan Sebagai Sumber Energi Listrik Alternatif. Jurnal Energi dan Manufaktur. Vol 9 No 2, Oktober 2016 .ISSN 2302 - 5255. Universitas Udayana, Bali. 
